\title{
A doctor and a grenade
}

$\mathrm{W}$

hen the war on Iraq started on Mar. 21, 2003, I was a resident house officer in $\mathrm{Al}$ Wasiti Hospital, a tertiary centre for orthopedics and reconstructive surgery, in Baghdad.

In the following days, we struggled to cope with a huge number of casualties, which turned the place into chaos.

In the middle of the hospital lobby, we provided first aid and then sent the patients to the wards. There was no time to investigate, to expose or to examine.

On Apr. 9, 2003, a young boy wearing a military uniform was admitted with severe wounds. I bandaged his wounds and sent him to the ward.

Shortly after, I heard shouts from the ward, and when I hurried to see what was going on, I saw the patients running away from their beds in a state of panic.

They were shouting "a bomb, help, help." The boy I had just admitted was carrying a hand grenade!

When I entered the room, he was lying calmly in his bed. With a shallow voice he called me and slowly raised his hand. It was the first time I saw a real grenade. I approached him and he said, faintly, "Please doc, can you throw this away?"

Without a moment of hesitation, I walked steadily to his bed, took the grenade, and then walked through the ward in front of horrified patients. I took it to a far and safe place outside the hospital, buried it and then marked its spot with a sign.

When I returned to the hospital, the staff and patients asked me how could I risk my life in such a way? How could I carry a grenade that could have

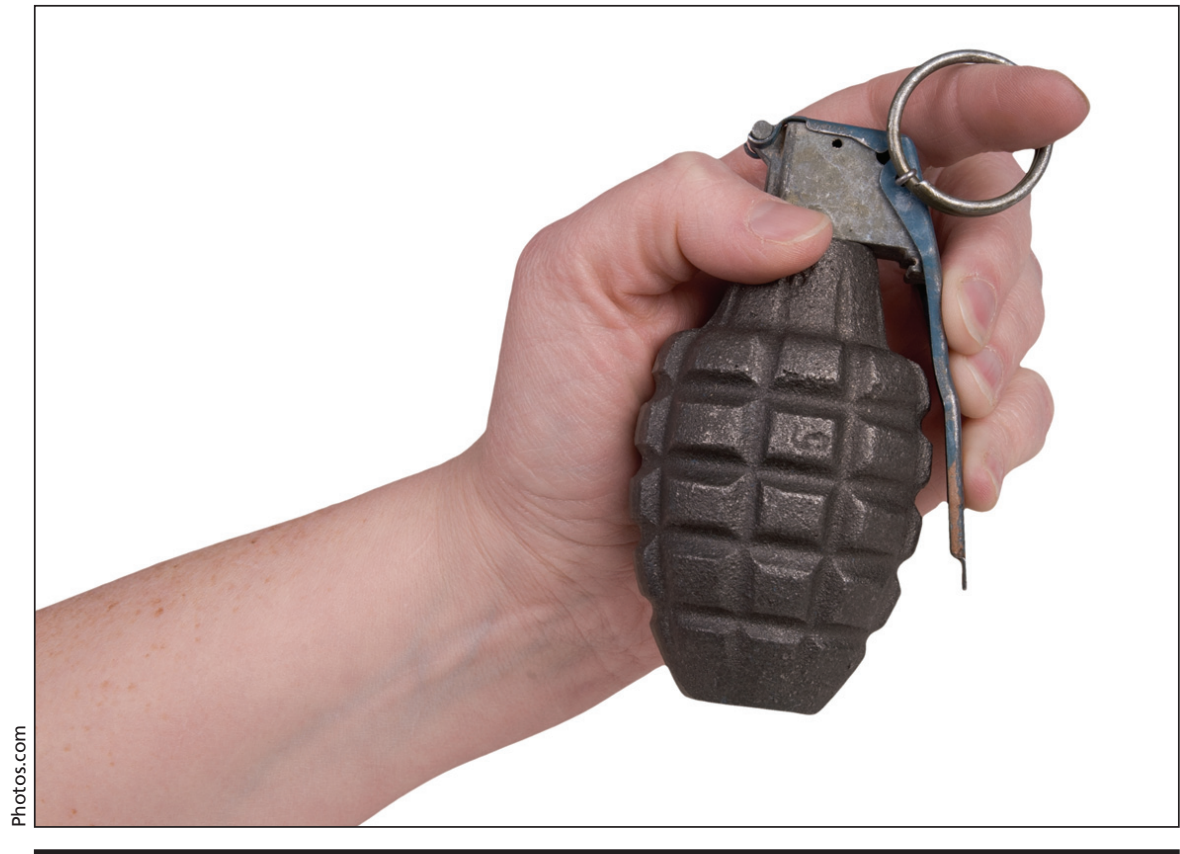

Dr. Yasir Hameed recalls taking a grenade from a patient's hand, walking it through the wards and then burying it outside the hospital.

exploded at any moment?

My answer was simple: I do not know. I was just thinking about the safety of my colleagues and patients, I was not thinking about myself.

The next day, I approached the US marine officer responsible for protecting our hospital from the looting that followed after the regime fell and the grenade was safely removed.

I remember that incident each time I feel tired or stressed out because of my work.

We spend our lives working for the health and well-being of others without thinking much about ourselves. We neglect ourselves, family and even our religious and social commit- ments. We feel happy when our patients improve and we feel relieved by their comfort. To that noble cause, we have dedicated our life. - Yasir Hameed, MD, Taiz, Yemen

DOI:10.1503/cmaj.091127

CMAJ invites contributions to "Dispatches from the medical front," in which physicians and other health care providers offer eyewitness glimpses of medical frontiers, whether defined by location or intervention. Submissions, which must run a maximum 700 words, should be forwarded to: wayne.kondro @ cmaj.ca. 